\title{
EL ARTE RUPESTRE DE LA LOCALIDAD ARQUEOLÓGICA LA GRUTA (PATAGONIA, ARGENTINA)
}

\section{AGUSTÍN ACEVEDOa}

\section{RESUMEN}

En este trabajo se presentan los resultados iniciales del análisis del arte rupestre registrado en seis sitios distribuidos en dos sectores vecinos de la localidad arqueológica La Gruta (Santa Cruz, Patagonia, Argentina), de los cuales sólo dos habían sido previamente descriptos e interpretados -en forma aislada- por otros investigadores (Menghin, 1952; Gradin \& Aguerre, 1983; Belardi \& Carballo Marina, 2005). Los resultados del estudio comparativo entre el arte rupestre de estos dos sectores de La Gruta muestran diferencias entre ellos a tres escalas: de sitio, de panel y de motivos. Se sostiene que estas diferencias son indicativas de la existencia de dos formas distintas de marcación visual del terreno vinculadas con diferentes estrategias de ocupación del espacio en dos sectores relativamente similares de una pequeña localidad arqueológica de ca. $6,5 \mathrm{~km}^{2}$. argentina.

PALABRAS CLAVE: arte rupestre, marcación visual del espacio, utilización de sitios, Patagonia

\section{ROCK ART AT LA GRUTA LOCALITY (PATAGONIA, ARGENTINA)}

\begin{abstract}
In this paper we present the initial results of the analysis of the rock art recorded in six sites distributed in two neighboring sectors of La Gruta locality (Santa Cruz, Patagonia, Argentina). Of these sites two were described and interpreted, in isolated form, by other researchers (Belardi \& Carballo Marina, 2005; Gradin \& Aguerre, 1983; Menghin, 1952). The results from the comparative study between the rock art of the two sectors of La Gruta show differences between them at three scales: site, panel and motifs. We suggest that these differences are indicative of the existence of two different ways of marking the space with rock art motifs related to different space occupation strategies in two relatively similar sectors of a small archaeological locality of ca. $6,5 \mathrm{~km}^{2}$.
\end{abstract}

KEY WORDS: rock art, space visual marking, using sites, Patagonia argentina. 


\section{INTRODUCCIÓN}

La localidad arqueológica de La Gruta se encuentra ubicada en el centro de la provincia de Santa Cruz (Patagonia, Argentina), en la región Extremo Sur del Macizo del Deseado (ESMD), al norte del río Chico (Fig. 1a). La misma se caracteriza por un relieve irregular que alterna lomadas suaves y cerritos aislados con lagunas temporales limitadas por afloramientos rocosos de areniscas e ignimbritas que poseen en su interior aleros y oquedades de diferentes tamaños (Panza \& Marín, 1998; Franco et al. 2010, 2012).

Hasta el momento, las investigaciones arqueológicas -sistemáticas- desarrolladas en esta localidad se han focalizado en dos sectores (dos lagunas muy cercanas entre sí) denominados Laguna 1 y Laguna 2 (Franco et al. 2010), separados por una distancia aproximada de $1,2 \mathrm{~km}$ (Fig. 1b). Publicaciones previas han descripto e interpretado el arte rupestre de La Gruta en forma parcial (Gradin \& Aguerre, 1983; Menghin, 1952; Franco et al. 2013). Trabajos recientes, realizados en el marco de los proyectos en que se desarrolla este análisis, han mostrado evidencias de ocupaciones humanas desde la transición Pleistoceno-Holoceno hasta el Holoceno tardío (Franco et al. 2010; Brook et al. 2015) y han evaluado -mediante distintos métodos- la existencia de episodios de humedad $y$ aridez, relacionados con la presencia humana en la localidad (Brook et al. 2013; Mancini et al. 2013; Brook et al. 2015).

En este trabajo, se presentan los resultados iniciales del análisis del arte rupestre de La Gruta registrado en seis sitios distribuidos entre los afloramientos rocosos de areniscas e ignimbritas que bordean las Lagunas 1 y 2 (Fig. 1b). Los seis sitios analizados incluyen: dos previamente identificados por otros investigadores (sitios La Gruta 4 y La Gruta 6) y cuatro nuevos sitios identificados y registrados por nuestro equipo (La Gruta 1, 2, 3 y 5). El objetivo de este análisis consiste en comparar el arte rupestre de ambas lagunas, evaluar la existencia de semejanzas y diferencias, y examinar si las diferencias halladas son indicativas de la presencia de dos formas diferentes de marcación visual del espacio en dos sectores relativamente próximos de una pequeña localidad.

\section{MARCO TEÓRICO}

Producir arte rupestre implica utilizar el espacio modificando sus rasgos naturales mediante la imposición de imágenes visuales sobre soportes rocosos fijos (Conkey, 1984; Bradley et al. 1994; Aschero, 1997; Fiore, 2016; Fiore \& Acevedo, 2017; entre otros). Esta marcación visual del espacio involucra operaciones de selección vinculadas -en partecon distintas estrategias de movilidad y uso de los recursos disponibles en el ambiente. Esto se

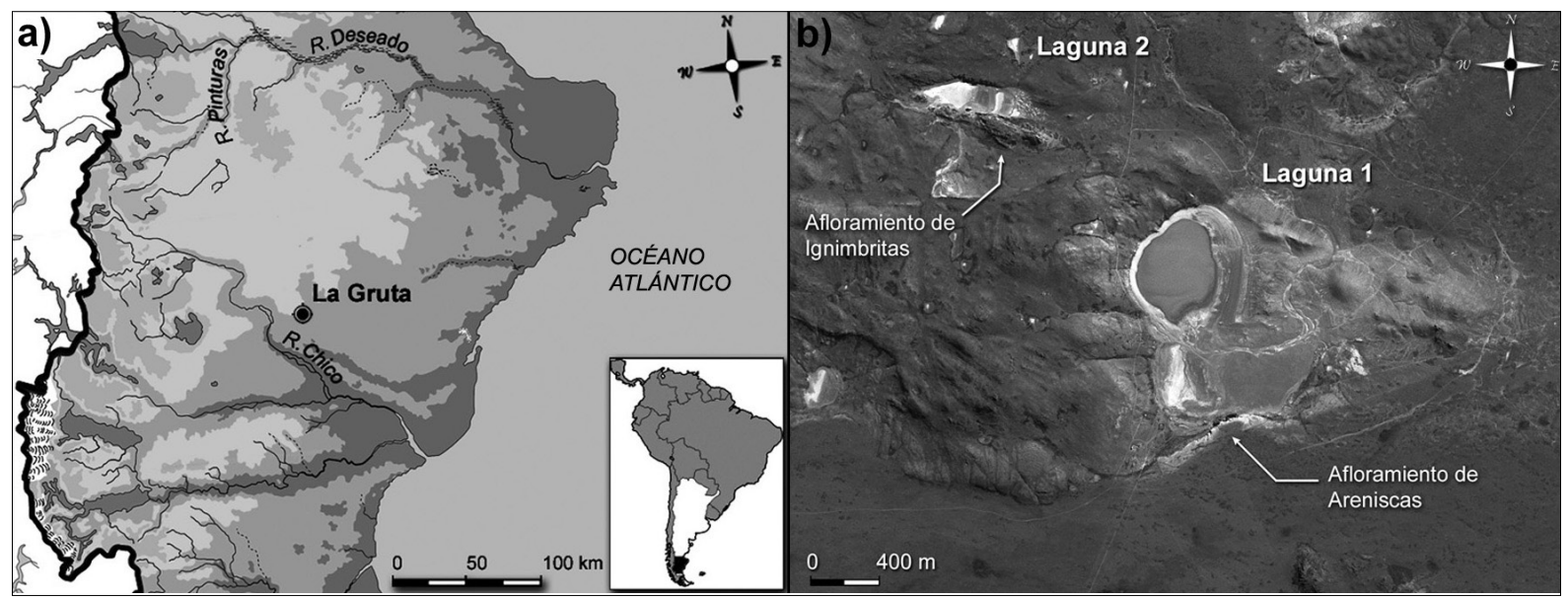

Fig. 1. a) Mapa de Santa Cruz con ubicación de la localidad La Gruta;

b) localidad La Gruta con ubicación de las lagunas y sus respectivos afloramientos rocosos. 
debe a que los grupos cazadores-recolectores no se mueven de forma azarosa, sino que lo hacen siguiendo patrones de movilidad que obedecen a diferentes estrategias adoptadas en función de los conocimientos que poseen del ambiente y sus recursos, de sus tecnologías y de sus relaciones con otros grupos (Conkey, 1984; Bradley et al. 1994, entre otros). El arte rupestre -por su naturaleza inmóvil- tiene la capacidad de marcar lugares significativos en el terreno, reflejando elecciones humanas dentro de un espacio (Bradley et al. 1994; Aschero, 1997). Esta cualidad convierte al estudio del arte parietal en una vía de análisis relevante para investigar distintas formas de acción humana sobre el espacio en el pasado (Jochim, 1983; Bradley et al. 1994; Aschero, 1997; Fiore, 2006; Carden, 2008, entre otros). Ejemplo de ello resultan los análisis de la relación entre cantidad y diversidad (técnica y formal) de las representaciones rupestres, tamaño de los emplazamientos utilizados $e$ intensidad de ocupación, para la generación de hipótesis sobre formas de ocupación del espacio a partir del estudio de las producciones rupestres (Aschero, 1997; Carden, 2007; Fiore \& Acevedo, 2016).

Existe un amplio consenso dentro de la Arqueología de Patagonia en pensar la movilidad de los grupos cazadores-recolectores en términos de dos estrategias complementarias: movilidad residencial y logística (sensu Binford, 1980). En términos sintéticos la movilidad residencial consiste en el movimiento de bandas o grupos de un campamento base a otro, mientras que la movilidad logística consiste en el movimiento de pequeños grupos de trabajo, que se desplazan desde la base residencial hasta lugares productivos, en términos de algún recurso determinado, para realizar tareas extractivas específicas (Binford, 1980). Ambas estrategias generan -en los extremos de un continuum ideal- dos grandes clases de sitios, susceptibles de ser identificados en el registro arqueológico -incluyendo el rupestre- (Binford, 1980; Aschero, 1996, 1997): sitios multipropósitos (por ej. bases residenciales) y sitios de actividades específicas (por ej. locaciones, campamentos operativos, estaciones, etc.).

Las bases residenciales se definen como el centro de las actividades de subsistencia de un grupo, el lugar donde la mayoría de los individuos permanecen por más tiempo, se realizan la mayor parte de las actividades de procesamiento, manufactura y mantenimiento y desde donde se desprenden las partidas especiales de trabajo (Binford, 1980). Un dato adicional importante es que, en escenarios ambientales que disponen de pocos lugares con recursos críticos -como podría ser el caso del agua en Patagonia-, el uso de las bases residenciales suele reiterarse a lo largo del tiempo (Binford, 1980). Por todo ello, las expectativas de producción rupestre para esta clase de sitios incluyen: a) la utilización de emplazamientos grandes, capaces de albergar varios individuos; b) con un número importante de motivos, tipos de motivos, técnicas, colores y superposiciones (Aschero, 1996, 1997).

Los sitios logísticos, por su parte, son lugares funcionalmente específicos que albergan grupos de trabajo pequeños por cortos periodos de tiempo (Binford, 1980). Por estas razones, las expectativas de producción rupestre son menores que las anteriores en términos de cantidad y variedad, incluyendo: a) la utilización de emplazamientos grandes, medianos y/o pequeños, capaces de albergar grupos de pocos individuos; b) constituidos por pocos motivos, tipos de motivos, técnicas, colores y superposiciones (Aschero, 1996, 1997).

El presente análisis del arte rupestre de La Gruta en función de las expectativas señaladas constituye un intento por generar información sobre distintas formas de uso del espacio, que sirva de base para la elaboración de inferencias e hipótesis contrastables estratigráficamente sobre las características de las ocupaciones humanas de la localidad a través del tiempo.

\section{DESCRIPCIÓN DE LA LOCALIDAD ARQUEOLÓGICA Y ANTECEDENTES}

Como fuera mencionado con anterioridad, los trabajos arqueológicos desarrollados en La Gruta se han focalizado en torno de dos lagunas, muy cercanas entre sí, denominadas como Laguna 1 y Laguna 2 (Franco et al. 2010). Ambas depresiones se encuentran limitadas en su costa sur por afloramientos rocosos (Fig. 1b). En el caso de la 


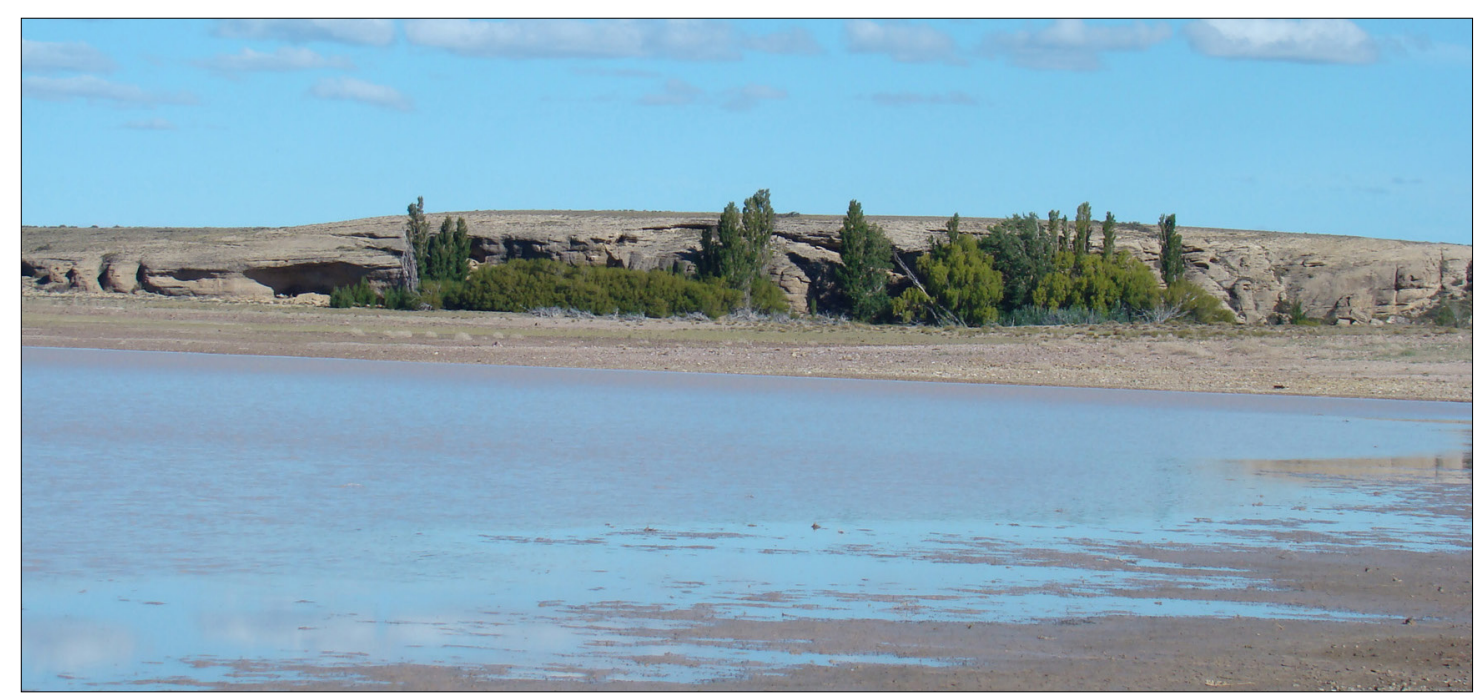

Fig. 2. Vista del afloramiento de areniscas que bordea la Laguna 1 de La Gruta.

Laguna 1, se trata de un afloramiento de areniscas coquinoideas grises y amarillentas, perteneciente a la Formación Monte León (Panza \& Marín, 1998), que se presenta como un borde de meseta pequeña, formando a nivel de la laguna un frente rocoso vertical de ca. $1.000 \mathrm{~m}^{\mathrm{de}}$ extensión ${ }^{1}$ (Fig. 2). Dentro de este afloramiento se identificó la presencia de cuatro sitios con arte (La Gruta 2, 3, 5 y 6) cuya producción rupestre consiste principalmente de motivos pintados en diferentes tonalidades de color rojo (rojo, rojo oscuro, rojo claro, rojo suave, rojo pálido, etc.), con escasos grabados, entre los que se incluyen tridígitos, negativos y positivos de manos y geométricos simples ejecutados con líneas continuas y/o mediante encadenamiento de puntos (por ej. meandros, zigzags, líneas curvas y óvalos, entre otros). El estado de conservación del arte oscila entre bueno, regular y malo $^{2}$, siendo este último el más frecuente (72\% de los casos). El principal efecto de la mala conservación de las pinturas se debe a la pérdida de color de los motivos, muchos de los cuales son prácticamente imperceptibles requiriendo para su visualización de la utilización del software DStretch-ImageJ (Harman, 2008) (Fig. 3). Dado que las areniscas

1 Las mediciones de los afloramientos rocosos (longitud y perimetro) se realizaron con Google Earth, por lo que deben considerarse solamente como aproximadas.

2 Según nuestro protocolo de relevamiento de campo, la definición de los estados de conservación de los motivos coquinoideas, que sirven de soporte a la producción rupestre, se encuentran estratificadas por erosión diferencial (sensu Panza \& Marín, 1998), no podemos descartar la existencia de situaciones de desprendimiento de losas o fragmentos de tamaño considerable que hayan arrastrado consigo motivos o paneles enteros.

En el caso de la Laguna 2, se trata de un afloramiento de ignimbritas silicificadas de color castaño oscuro a rojizo y morado, perteneciente a la Formación Chon Aike (Panza \& Marín, 1998), que se presenta en forma de un cerrito aislado de ca. $1.000 \mathrm{~m}$ de perímetro (Fig. 4). En el interior de este afloramiento se identificaron dos sitios con arte (La Gruta 1 y La Gruta 4) conteniendo una producción rupestre exclusivamente pintada (también en diferentes tonalidades de rojo) y un repertorio de imágenes dominado por la presencia de negativos de manos. El estado de conservación del arte -en términos generales- es malo (73\% de los casos), con excepción de unos pocos motivos que se encuentran en estado regular y, en menor medida, bueno. La señal más notoria de mala conservación en las pinturas nuevamente es la pérdida de color de los motivos, los cuales

(Muy Bueno, Bueno, Regular y Malo), surge de la interrelación de los estados registrados en cuatro variables: 1) integridad morfológica (alta, media, baja); 2) intensidad de color y contraste (alta, media, baja); 3) obliteración (alta, media, baja); y, 4) remoción (alta, media, baja). 
se encuentran muy desvaídos. Adicionalmente, también se observó la presencia de pátinas, fisuras y descascaramientos de la roca soporte, aunque no en tanta frecuencia como la pérdida de color ya mencionada (Fig. 5).

El arte rupestre presente en los afloramientos que bordean una y otra laguna ha sido descripto $e$ interpretado, en forma breve y parcial, por distintos investigadores desde 1950 hasta el presente. En el afloramiento de areniscas de la Laguna 1 Menghin (1952) identificó una pequeña oquedad con huellas de pinturas y otra oquedad más grande con una composición formada por manos, líneas onduladas, un círculo con radios y un número importante de tridígitos grandes, o flechas, que interpretó como la representación de una leyenda tehuelche (Menghin, 1952; Fig. 6). Ambas oquedades actualmente forman parte de un gran alero denominado La Gruta 6. Menghin (1957) atribuyó estas pinturas a su "Estilo de pisadas", que vinculó temporalmente con el Tehuelchense Antiguo (2.000 años AC a 0) y Tehuelchense Medio (0 a 1.400 años DC). Posteriormente, Gradin \& Aguerre (1983) estudiaron las mismas pinturas descriptas por Menghin (1952, 1957; ver Fig. 6) y las adscribieron al Grupo C del área del río Pinturas, o a una fase final del Grupo B.1, que vincularon con la Tradición Casapedrense (2.500 años AC). Adicionalmente identificaron en el mismo sitio un conjunto de motivos pintados de color rojo que no había sido mencionado por Menghin (1952), constituido por trazos escalonados, serpentiformes y líneas zig-zag. Este conjunto fue asignado por Gradin \& Aguerre (1983) al Grupo E correspondiente al Complejo Patagoniense, presente en la región a partir de 300 años DC. Más recientemente, en el marco de los trabajos realizados por nuestro equipo, Franco (2007) y Franco \& Cattaneo (2009) identificaron

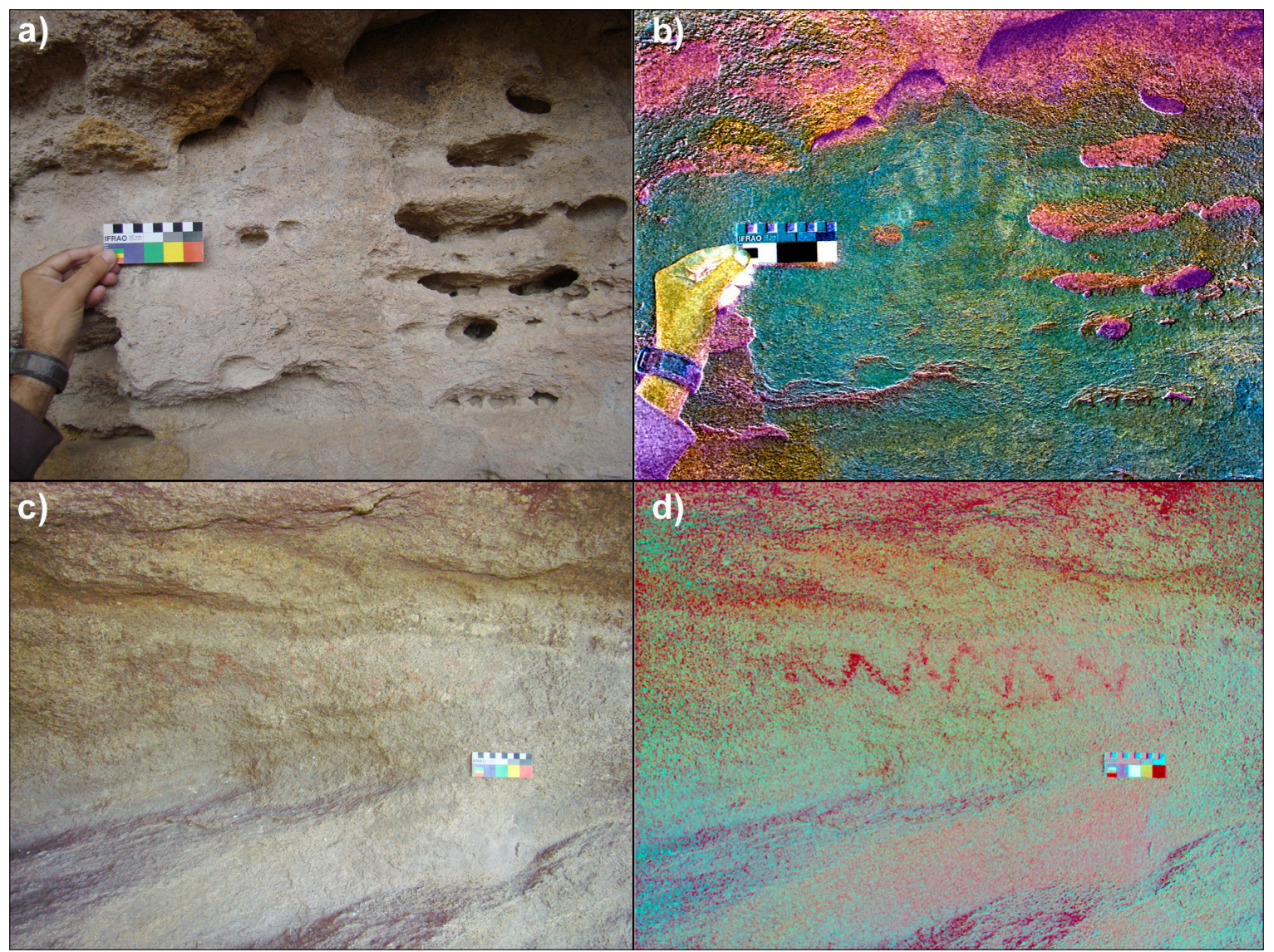

Fig. 3. Ejemplos de estados de conservación de los motivos presentes en el afloramiento de areniscas de Laguna 1: (a y c) imágenes originales de motivos decolorados; (b y d) imágenes procesadas con DStretch-ImageJ (Harman, 2008). 


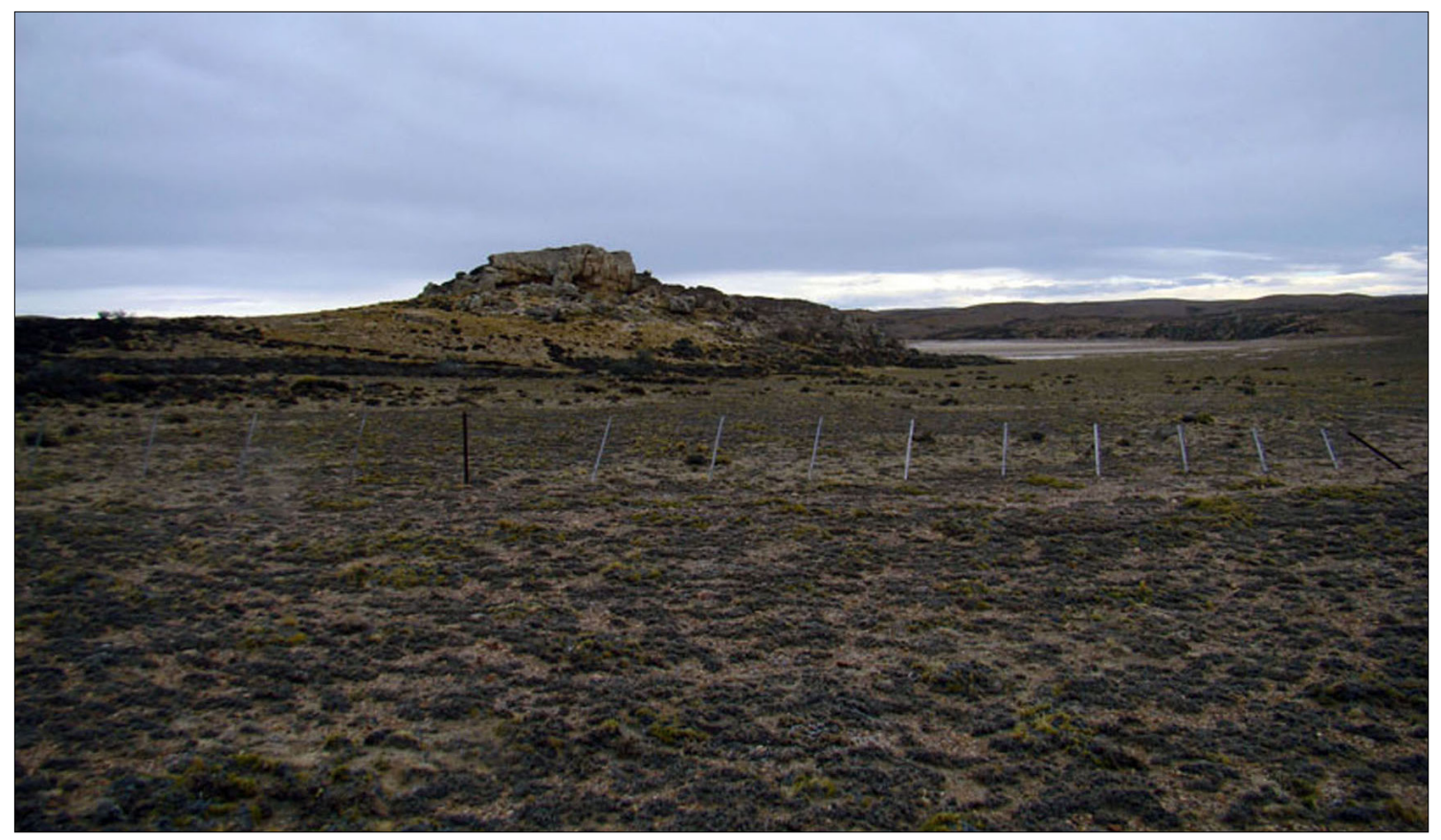

Fig. 4. Vista del afloramiento de ignimbritas que bordea la Laguna 2 de La Gruta.

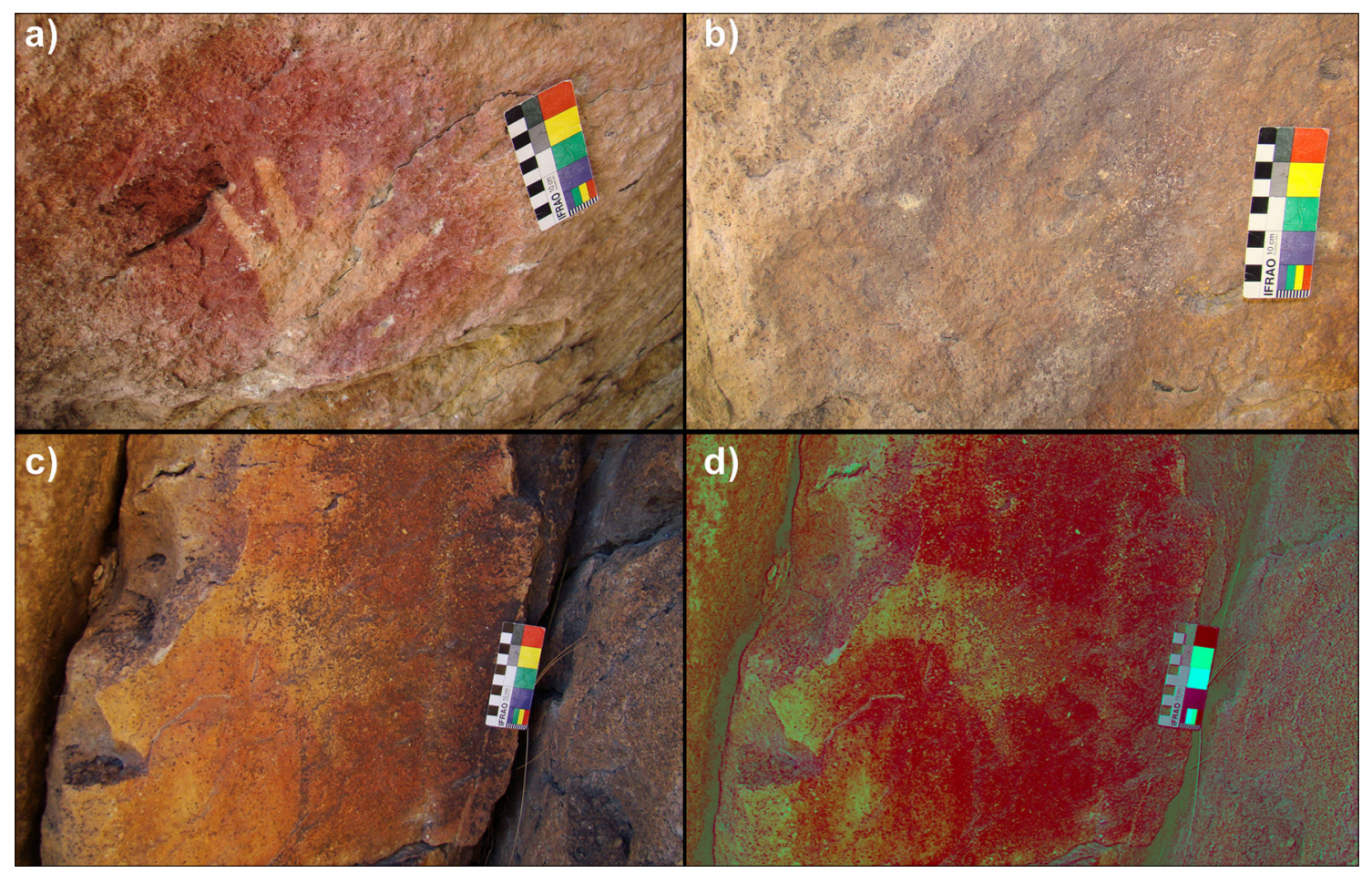

Fig. 5. Ejemplos de estados de conservación de los motivos presentes en el afloramiento de ignimbritas de Laguna 2: (a) negativo de mano afectado por fisura en la roca soporte;

(b) negativo de mano afectado por líquenes; (c) negativo de mano decolorado; (d) imagen anterior (c) procesada con DStretch-ImageJ (Harman, 2008). 
un pequeño alero con una serie de puntos rojos y negros pintados (actualmente denominado La Gruta 2; Fig. 7). Excavaciones posteriores realizadas en este sitio permitieron obtener un fechado de ca. 7.500 años AP para un hueso de guanaco (Lama guanicoe) con marcas de corte (Franco et al. 2013; Brook et al. 2015). Si bien el sitio La Gruta 6 (previamente registrado por Menghin y Gradin \& Aguerre) no pudo ser excavado por cuestiones relacionadas con la perturbación del registro, sí se pudieron realizar excavaciones en el sitio lindante La Gruta 3 (Brook et al. 2015; Cirigliano, 2016). Estas excavaciones permitieron interpretar el sitio como un espacio de actividades múltiples, posiblemente de carácter residencial, para el lapso comprendido entre ca. 400 y 200 años AP (Cirigliano, 2016), a partir de dataciones realizadas sobre carbones provenientes de un fogón y huesos de guanaco con marcas de corte (Brook et al. 2015). En este punto cabe señalar que, dada la presencia humana temprana en la localidad y el estado inicial de las excavaciones en el sitio La Gruta 3, no se descarta la posibilidad de obtener fechados más tempranos en la medida en que avancen las investigaciones.

En el afloramiento de ignimbritas de la Laguna 2, en un contexto de trabajos de impacto realizados en la localidad, Belardi \& Carballo Marina (en Vector, 2005) identificaron un alero con negativos de manos rojos y anaranjados (actual sitio La Gruta 4; Fig. 8). Posteriormente, en este mismo sitio (La Gruta 4), Franco (2007) y Franco \& Cattaneo (2009) identificaron nuevos negativos de manos. En forma adicional, las autoras (Franco, 2007; Franco \& Cattaneo, 2009) también registraron la presencia de negativos de manos rojos en un alero de pequeñas dimensiones (actual sitio La Gruta 1), que no había sido descripto hasta el momento, localizado en un sector elevado del afloramiento que presenta buena visibilidad

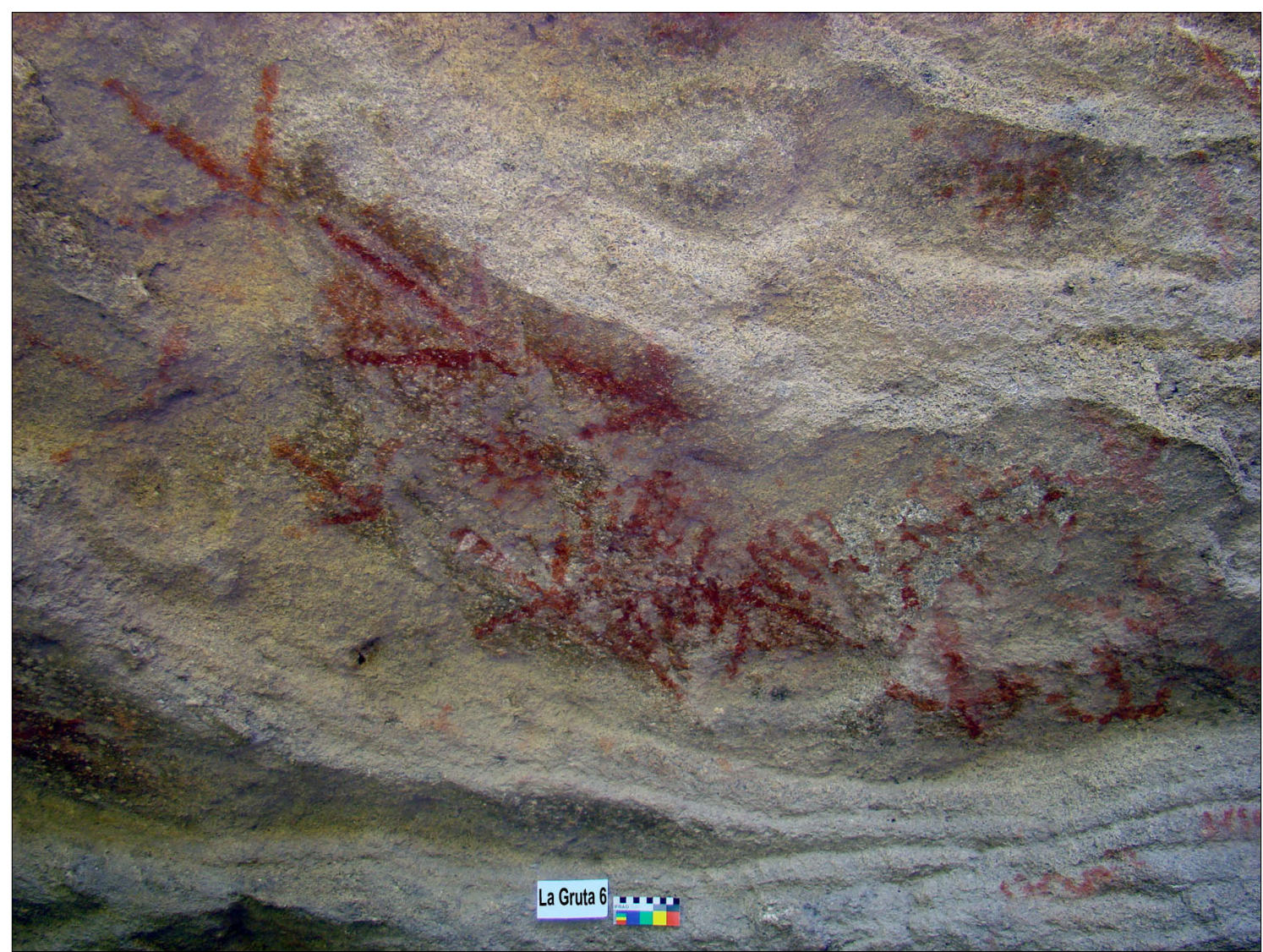

Fig. 6. Conjunto de motivos pintados que fuera descripto por Menghin (1952) y Gradin \& Aguerre (1983) (sitio La Gruta 6 ubicado en Laguna 1). 


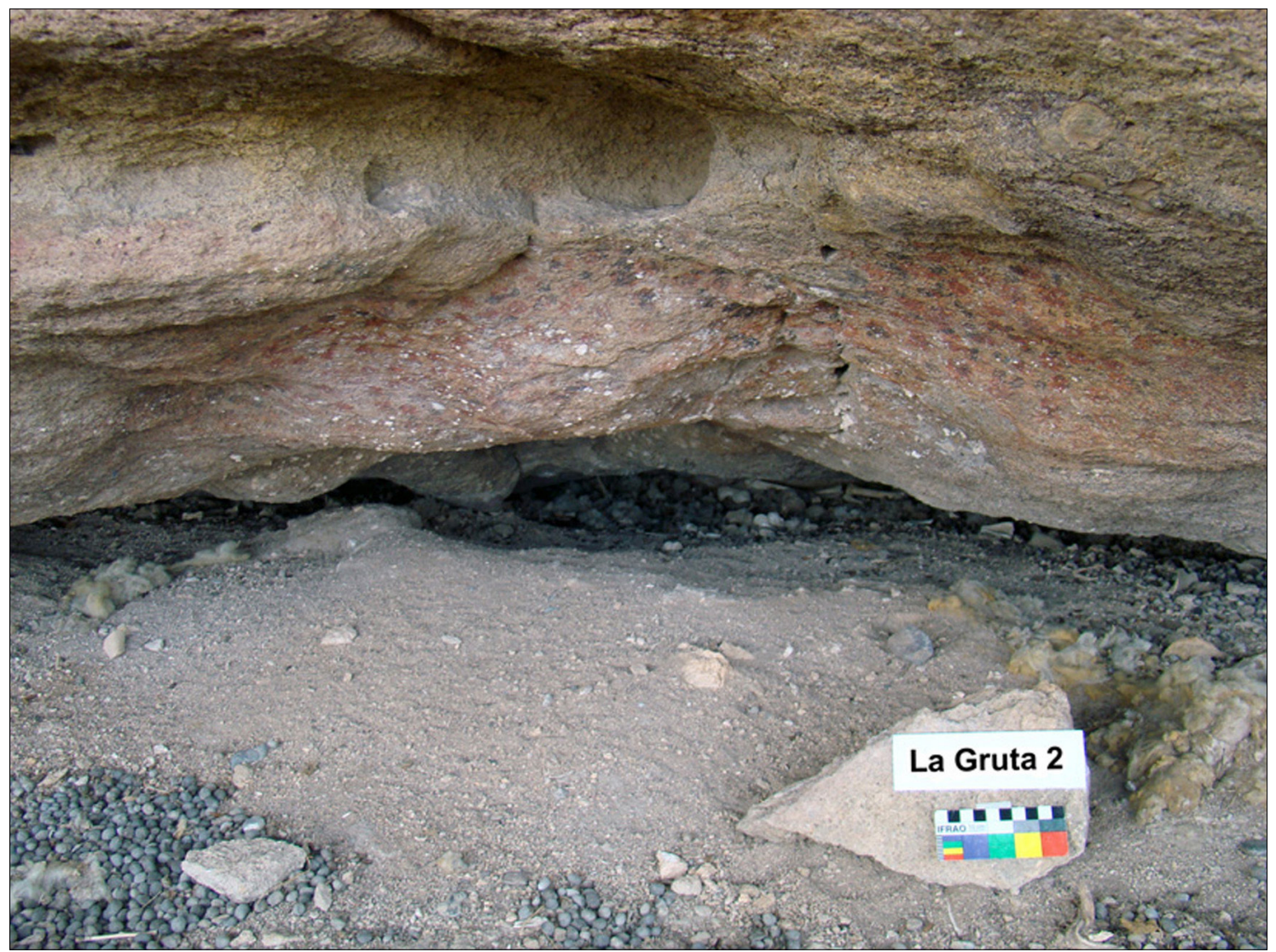

Fig. 7. Conjunto de puntos rojos y negros identificados por Franco (2007) y Franco \& Cattaneo (2009) (sitio La Gruta 2 ubicado en Laguna 1).

hacia la Laguna 2 (Franco et al. 2010). En este último alero se realizaron excavaciones que proporcionaron fechados comprendidos entre la transición Pleistoceno-Holoceno y el Holoceno tardío (ca. 10.800 a 400 años AP), cuyos resultados preliminares permitieron interpretarlo como un lugar de funciones logísticas relacionadas con actividades de avistamiento y/o caza de guanacos (Franco et al. 2010; Mancini et al. 2013; Brook et al. 2015).

\section{METODOLOGÍA}

Sobre la base del conocimiento de las características topográficas de la localidad y de los trabajos previos realizados por otros investigadores, se realizó un relevamiento sistemático de arte rupestre en la totalidad de las superficies de cada uno de los afloramientos rocosos próximos a cada laguna. Ello permitió relocalizar los sitios previamente publicados por Menghin (1952), Gradin \& Aguerre (1983) y Belardi \& Carballo Marina (en Vector, 2005), e identificar nuevos sitios y nuevos motivos, incluso en los sitios que ya habían sido relevados.

\section{Etapa de recolección de datos}

En los casos en que se observó la presencia de arte rupestre, la información se registró en planillas diseñadas para recolectar datos a tres escalas: sitio, panel y motivo (Fiore, 2009; Fiore \& Acevedo, 2016). La definición de sitio adoptada en este trabajo remite a: una concentración discreta de motivos rupestres en el interior de soportes rocosos con límites precisables a partir de su morfología (por ej., alero, cueva, paredón) (Hernández Llosas, 1985; Re, 2010). A esta 


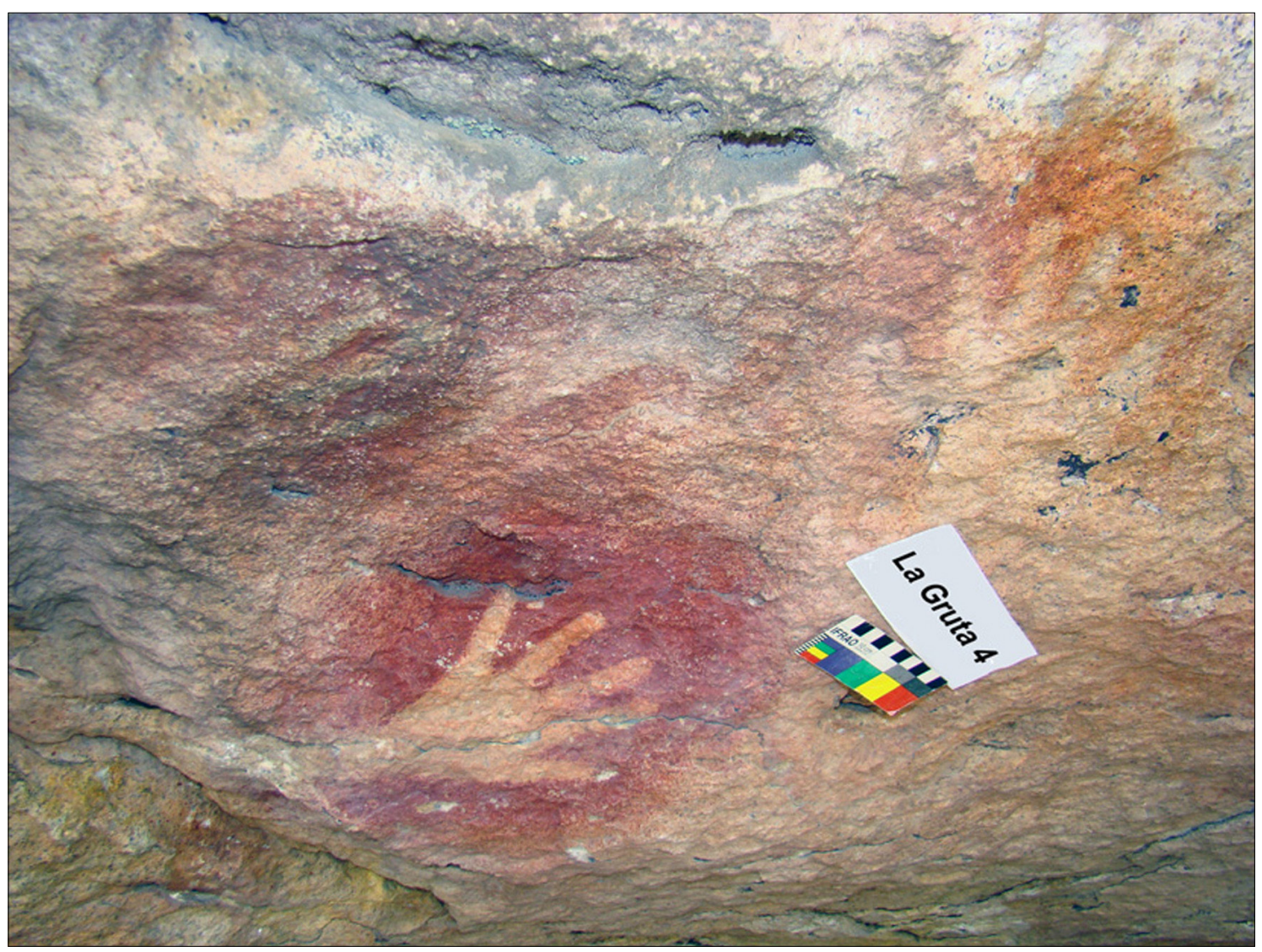

Fig. 8. Negativos de manos del sitio La Gruta 4 ubicado en Laguna 2.

escala se registró información sobre: a) número de sitio; b) coordenadas de latitud y longitud; c) orientación cardinal; d) tipo de morfología del sitio (por ej., cueva, alero, paredón; sensu Aschero, 1997); y f) número de paneles presentes en el sitio (Hernández Llosas, 1985; Llamazares, 1992; Loendorf, 2001; Fiore, 2009). La segunda escala de registro y análisis de información es el panel definido como: una unidad y/o porción discreta de soporte rocoso que contiene un motivo o dos o más motivos rupestres (relacionados visualmente entre sí por proximidad espacial), cuyos límites se establecen siguiendo criterios convencionales (por ej., circunscripción en torno a accidentes microtopográficos, espacios circundantes vacíos de imágenes $y / 0$ cambios significativos en la orientación del soporte) (Loendorf, 2001; Fiore \& Acevedo, 2017). A esta escala se registró información respecto de: a) número de panel; b) orientación cardinal; c) $\mathrm{N}$ de motivos presentes en el panel; y d) $\mathrm{N}$ de tipos de motivos presentes en el panel (Hernández Llosas, 1985; Llamazares, 1992; Loendorf, 2001; Fiore, 2009; Fiore \& Acevedo, 2016). Finalmente, la unidad mínima de registro y análisis de este trabajo es el motivo y se define como: la expresión gráfica resultante de la utilización de uno o varios elementos decorativos básicos (empleados de manera única, reiterada y/o combinada), ejecutada mediante un elemento único de trazo unitario y/o mediante elementos discretos con una proximidad espacial notoria entre sí que se unen para formar una sola entidad visual mayor (Aschero, 1988; Fiore, 2002; Fiore \& Acevedo, 2017; Gradin, 1978; Hernández Llosas, 1985). A esta escala se registró información sobre: a) número de motivo; b) tipo de motivo; c) técnica; d) color (en el caso de los motivos pintados); e) presencia/ausencia de superposiciones; y f) estado de conservación del motivo (integridad morfológica, intensidad de color y contraste, obliteración, 
remoción, presencia de pátinas, líquenes y grafitis, entre otros) (Hernández Llosas, 1985; Llamazares, 1992; Fiore \& Acevedo, 2016). Todo el proceso de recolección de información fue complementado con la aplicación del software DStretch-ImageJ (Harman, 2008) sobre las fotografías tomadas en el campo.

\section{Etapa de análisis de datos}

La información registrada en las planillas de relevamiento se volcó en una base de datos Excel de múltiples escalas (sensu Fiore, 2009) formada por tres tablas, una para cada escala (sitio, panel y motivo), interrelacionadas entre si $i^{3}$. Una vez completa la base de datos se procedió a la realización de análisis univariados y bivariados (formados por el cruce entre sí de dos de las variables registradas, cualesquiera sean) siguiendo un protocolo de cruces de variables diseñado para buscar tendencias cuantitativas significativas a los objetivos del trabajo de investigación (Fiore, 2009; Fiore \& Acevedo, 2016).

Para agilizar la búsqueda de similitudes y diferencias, los motivos (o imágenes rupestres) registrados se clasificaron en tipos y clases de motivos utilizando criterios centrados en la comparación de sus respectivas morfologías, definidas por la articulación de los elementos decorativos básicos que los componen (Fiore, 2011; Acevedo et al. 2012-14). De este modo, en un primer nivel de clasificación, los motivos que compartían rasgos morfológicos semejantes se agruparon dentro de tipos de motivos (por ej., mano negativa, positiva, tridígito, línea curva, etc.) (Hernández Llosas, 1985; Aschero, 1988; Fiore, 2011). En un segundo nivel de clasificación, los tipos de motivos vinculados entre sí por afinidades morfológicas y temáticas se agruparon en clases de motivos (por ej., manos, pisadas, geométricos simples, geométricos puntiformes y otros $^{4}$ ) (Fiore, 2011; Acevedo et al. 2012-14; Fiore \& Acevedo, 2016).

3 El vínculo entre las tres tablas está dado por los números de sitio, panel y motivo, así, por ejemplo: la tabla a escala de sitio se relaciona con la tabla a escala de panel porque en esta última cada panel posee indicación del número de sitio al cual pertenece; en la tabla a escala de motivo cada uno de ellos posee indicación del número de panel y número de sitio al que pertenece.
Finalmente, el análisis univariado y bivariado de la información se complementó mediante la elaboración y aplicación del índice de variabilidad NTM/NM, que divide la cantidad de tipos de motivos (NTM) por la cantidad de motivos (NM) de cada sector de la localidad, permitiendo obtener un valor comprendido entre 0 y 1 que es muy útil en términos comparativos (Fiore \& Acevedo, 2016). De este modo, cuando el resultado del índice se acerque más a 1, mayor será la variabilidad de tipos de motivos dentro de la muestra. Esto es así porque un resultado igual a 1 implica que por cada motivo de la muestra hay un tipo de motivo distinto, es decir: la muestra registra la máxima variabilidad de diseños posible (Fiore \& Acevedo, 2016).

En este punto es necesario aclarar que, por tratarse de una primera instancia de análisis, no se toman en cuenta los aspectos diacrónicos de la producción rupestre, sino que todos los motivos que actualmente conforman el repertorio visual de cada laguna son tratados como una totalidad acumulativa, considerando al arte rupestre como un fenómeno aditivo (Aschero, 1997). De este modo, las tendencias generales surgidas de los análisis realizados serán validas sólo para todos los motivos considerados en su conjunto, pero no reflejan continuidades o cambios diacrónicos en el arte rupestre. Esto es especialmente importante si se tiene en cuenta que, de acuerdo con la información disponible actualmente, la ocupación humana de la localidad fue discontinua (Franco et al. 2010; Mancini et al. 2013; Brook et al. 2015).

\section{RESULTADOS}

A continuación, se presentan los resultados obtenidos de los análisis comparativos realizados entre el arte rupestre del afloramiento de areniscas de la Laguna 1 (en adelante LAG1) y del afloramiento de ignimbritas de la Laguna 2 (en adelante LAG2).

4 Dentro de la clase de motivos "Otros" se agrupan cuatro tipos de motivos: arrastre de dedo, arrastres de dedos paralelos múltiples, manchas y grafitis. De estos cuatro tipos de motivos, los grafitis no serán abordados en este trabajo por tratarse de una primera instancia de análisis y obtención de tendencias generales. 
A escala de sitio

LAG1 tiene más sitios con arte rupestre que LAG2 ( $n=4$ vs. $n=2$; Fig. 9). En ambos sectores, éstos se encuentran emplazados en aleros (LAG1: $\mathrm{n}=4=100 \%$; LAG2: $\mathrm{n}=2=100 \%)$, orientados principalmente hacia el noroeste (NW: $\mathrm{n}=5 ; \mathrm{N}$ : $\mathrm{n}=1$; NE: $\mathrm{n}=1$ ), los cuales son más grandes en LAG1 que en LAG2 (Fig. 10). Esta tendencia, presente en ambos sectores, relativa a la localización del arte rupestre en aleros puede resultar de tres factores:

a. las características topográficas de cada sector (ausencia de cuevas y presencia de aleros, paredones y bloques);

b. temas relacionados con la conservación de las pinturas (paredones y bloques están más expuestos a los agentes ambientales y sus pinturas son más propensas a deteriorarse; ver Fiore, 2006); y/o

c. elecciones humanas (los aleros pueden haber sido intencionalmente escogidos por los productores de arte rupestre dadas sus condiciones de reparo y habitabilidad).

El análisis de la distribución de los sitios con arte en el interior de los afloramientos rocosos de uno y otro sector muestra que en el caso de LAG1 los sitios se encuentran distribuidos de manera relativamente continua a lo largo del afloramiento de areniscas (Fig. 9). En cambio, en LAG2 los sitios se concentran en los dos únicos aleros del afloramiento de ignimbritas (ubicados uno en cada extremo del mismo), dejando extensiones de paredones y bloques de gran tamaño, que potencialmente podrían ser soporte de producciones rupestres, sin utilizar (Fig. 9). En términos generales, ambos sectores tienden a emplazar la producción rupestre en lugares reparados (aleros) con buen dominio visual de las lagunas y sus alrededores (Fig. 9).

De forma esperable, dado su mayor cantidad de sitios, LAG1 presenta mayor cantidad de motivos que LAG2 ( $\mathrm{n}=114$ vs. $\mathrm{n}=33$ ). El análisis de la distribución de estos motivos entre los sitios de ambos sectores muestra que un solo sitio perteneciente al sector LAG1 (La Gruta 6) concentra el 52\% $(n=78)$ del total de la producción rupestre de la localidad. Los cinco sitios restantes exhiben producciones menores que oscilan entre ocho (La Gruta 5) y 23 motivos (La Gruta 4) (Fig. 11). El mismo análisis realizado a nivel de tipos y clases de motivos muestra que, en términos generales, los sitios del sector LAG1 exhiben repertorios de imágenes más amplios (más tipos, más clases) que los sitios de LAG2 (Fig. 11). En función de lo expuesto, es posible observar que: a) LAG1

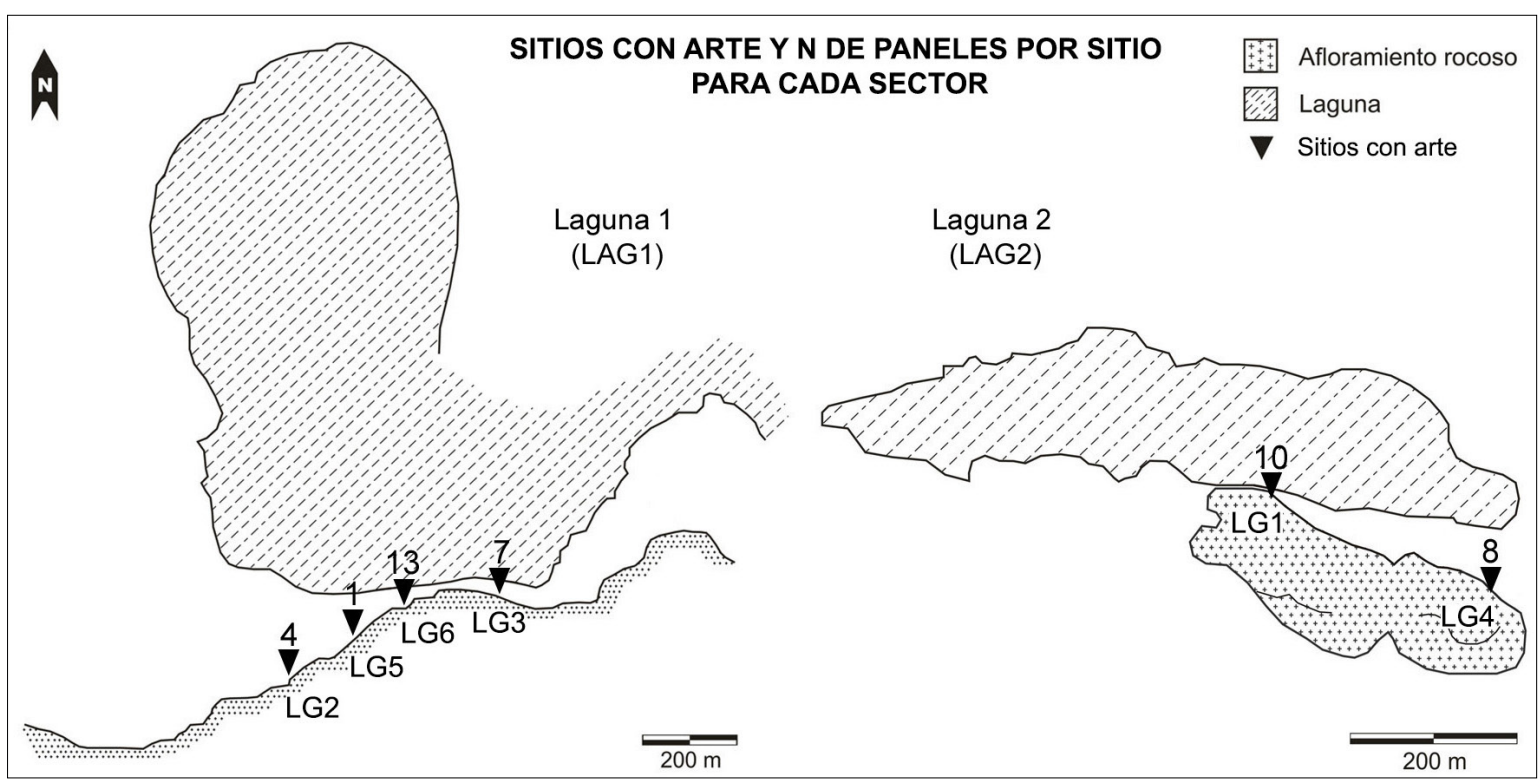

Fig. 9. Localización de los sitios con arte rupestre y distribución de los paneles entre los sitios en cada sector. 

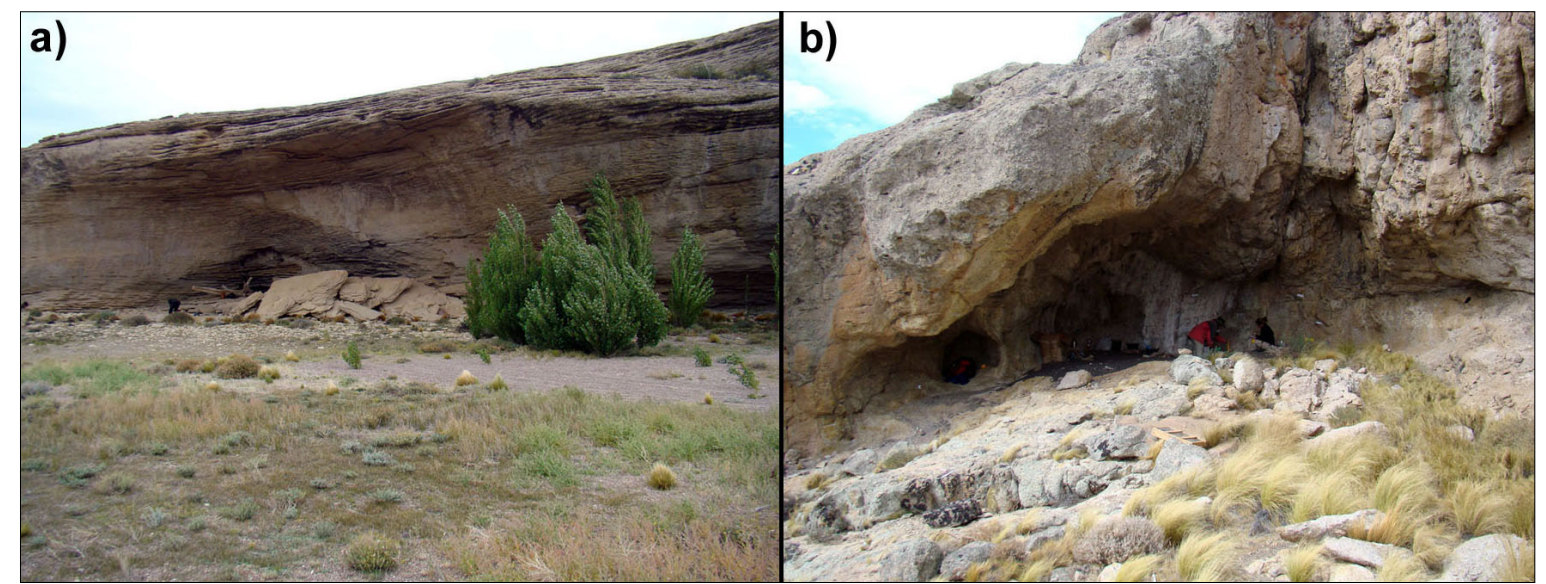

Fig. 10. Vista de los sitios: a) sitio La Gruta 3, ubicado en el afloramiento de areniscas de Laguna 1 (LAG1); b) sitio La Gruta 1, ubicado en afloramiento de ignimbritas de Laguna 2 (LAG2).

posee una producción rupestre más grande y más variada que LAG2; b) un solo sitio (La Gruta 6) concentra la mayor cantidad de motivos y tipos de motivos de toda la localidad (Fig. 11).

A escala de panel

LAG1 tiene más paneles con arte que LAG2 ( $\mathrm{n}=25$ vs. $\mathrm{n}=18$; Tabla 1), lo cual es estadísticamente esperable de acuerdo con el número de sitios presentes en cada sector (LAG1: $n=4$ vs. LAG2: $n=2$ ). Sin embargo, cuando se analiza la distribución de paneles entre sitios (ver
Fig. 9), se puede apreciar que -con excepción de La Gruta 6 que posee 13 paneles- la mayoría de los sitios de LAG1 tienen menos paneles que los dos sitios de LAG2 ( $\mathrm{n}=10$ y $\mathrm{n}=8$ ).

Ambos sectores exhiben diferencias en la cantidad de motivos involucrados en la composición de sus paneles con arte. En el caso de LAG2, la mayoría de los paneles ( $\mathrm{n}=16=88,9 \%$ de 18) están compuestos por pocos motivos (entre uno y tres); sólo dos tienen más de tres motivos y el panel que más motivos combina sólo posee cinco. En el caso de LAG1, en cambio, se observan frecuencias similares entre los paneles compuestos

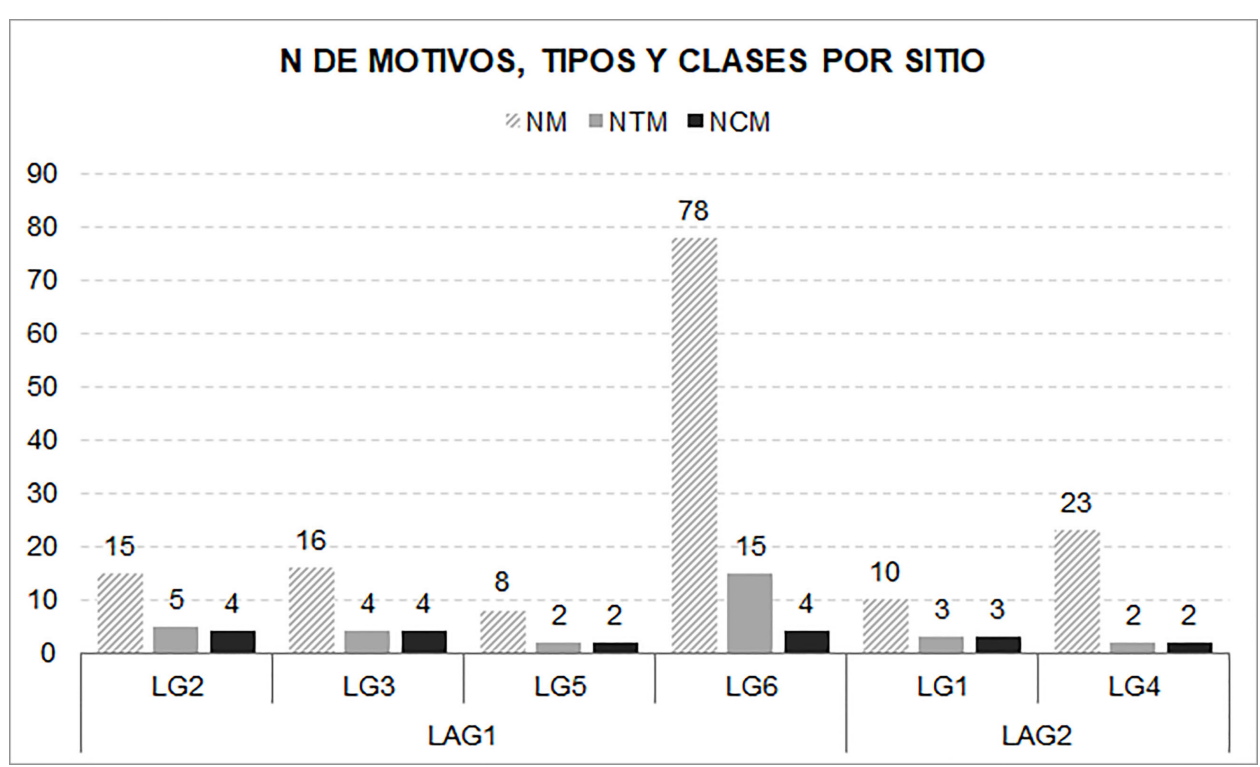

Fig. 11. Frecuencias de motivos, tipos de motivos y clases de motivos por sitios en ambos sectores. 
por más de tres motivos -y hasta un máximo de 23$(n=13=52 \%$ de 25$)$ y los compuestos por entre uno $y$ tres motivos $(n=12=48 \%)$. Resulta interesante destacar que ocho $(61,5 \%)$ de los 13 paneles con más de tres motivos se concentran en un solo sitio (La Gruta 6).

Por su parte, el análisis de los paneles a partir de la frecuencia de tipos de motivos utilizados en su composición muestra que, en ambos sectores, existe una tendencia a combinar pocos tipos de motivos por panel. En LAG1, los casos más frecuentes consisten en paneles con un solo tipo de motivo $(\mathrm{n}=9=36 \%$ ) y/o con dos tipos ( $n=9=36 \%)$. Por fuera de esta tendencia, el sector presenta siete paneles ( $28 \%$ de 25 ) que combinan tres y hasta cuatro tipos de motivos; seis de estos paneles se concentran en un único sitio (La Gruta 6). En el caso de LAG2, la mayoría de los paneles están formados por un solo tipo de motivo ( $\mathrm{n}=15=83,3 \%$ ), con unos pocos paneles $(\mathrm{n}=3=16,7 \%)$ que presentan hasta un máximo de dos tipos de motivos. Lo mismo ocurre al nivel de clases de motivos. En el caso de LAG1, 12 (48\%) de 25 paneles presentan sólo una clase de motivos, 9 paneles (36\%) presentan dos y cuatro paneles $(16 \%)$ entre tres y hasta cuatro clases. En el caso de LAG2, 15 (83,3\%) de 18 paneles presentan sólo una clase de motivos y tres paneles $(16,7 \%)$ dos clases de motivos. Nuevamente, al igual que a nivel de motivos y tipos de motivos, en el caso de LAG1, ocho $(61,5 \%)$ de los 13 paneles que combinan motivos de entre dos $\mathrm{y}$ hasta cuatro clases se concentran en un único sitio (La Gruta 6).

En función de lo expuesto es posible observar la existencia de dos patrones diferentes de distribución y composición de paneles con arte: a) en el caso de LAG2 un patrón más homogéneo o regular, con sitios que exhiben frecuencias similares de paneles compuestos por pocos motivos, tipos y clases; $y, b)$ en el caso de LAG1 un patrón más heterogéneo o irregular, con un sitio (La Gruta 6) que concentra la mayor cantidad de los paneles del sector y los paneles con mayor cantidad de motivos, tipos y clases de motivos.

\section{A escala de motivo}

LAG1 posee frecuencias más altas de motivos, tipos, clases de motivos y técnicas en relación con LAG2, lo cual es esperable dado su número más elevado de sitios y paneles (Tabla 2).

LAG1 presenta un repertorio de 18 tipos de motivos que incluye: tridígitos, manos negativas, positivas y contorneadas, meandros, óvalos, zigzags, puntos agrupados en líneas rectas paralelas $y$ en formas indeterminadas, circunferencias radiadas y líneas curvas, entre otros (Fig. 12). Estos tipos de motivos se agrupan en 5 grandes clases: geométricos simples, manos, pisadas, geométricos puntiformes y otros. Por su parte, LAG2 muestra un repertorio acotado a tres tipos de motivos: manos negativas, tridígitos y manchas; que se agrupan en tres clases de motivos: manos, pisadas y otros (Fig. 12). Por lo tanto, los repertorios de tipos y clases de motivos de uno y otro sector son diferentes, más grandes en LAG1 que en LAG2, lo cual es coherente con el tamaño de cada muestra (Tabla 2 y 3).

Los tipos de motivos más frecuentes en ambos sectores son diferentes: tridígitos en LAG1 $(n=28=24,6 \%)^{5}$ y manos negativas en LAG2 ( $n=26=81,8 \%)$. Lo mismo ocurre con las clases de motivos: pisadas en LAG1 $(n=28=24,6 \%)$ y manos en LAG2 ( $\mathrm{n}=26=81,8 \%$ ). Es interesante notar que estos tipos y clases de motivos se comparten entre

Tabla 1. Síntesis de resultados a escala panel.

\begin{tabular}{lcc}
\hline & LAG1 & LAG2 \\
\hline N de Paneles & 25 & 18 \\
Frecuencia máxima de motivos por panel & 23 & 5 \\
Frecuencia máxima de tipos de motivos por panel & 4 & 2 \\
Frecuencia máxima de clases de motivos por panel & 4 & 2 \\
\hline
\end{tabular}

5 El conteo excluye las manchas de pintura $(n=36=31,6 \%)$. 
Tabla 2. Síntesis de resultados a escala motivo.

\begin{tabular}{lcc}
\hline & LAG1 & LAG2 \\
\hline N de motivos (NM) & 114 & 33 \\
N de tipos de motivos (NTM) & 18 & 3 \\
N de clases de motivos & 5 & 3 \\
Técnicas & 4 & 3 \\
Tipos de motivos más frecuentes & Tridígitos & Manos negativas \\
Tipos de motivos compartidos & Manos negativas \& Tridígitos \\
Clases de motivos compartidas & \multicolumn{2}{c}{ Manos \& Pisadas } \\
Técnica más frecuente & Pintura Positiva & Pintura Negativa \\
Indice NTM/NM & 0,15 & 0,09 \\
N de superposiciones & 5 & 3 \\
\hline
\end{tabular}

ambos sectores, pero en cada uno están presentes en orden inverso de frecuencias (Tabla 3).

El análisis de la distribución inter-sitios de los tipos de motivos muestra que, de forma esperable, los dos tipos más frecuentes son los más distribuidos entre los sitios de la localidad: manos negativas presentes en los seis sitios de La Gruta y tridígitos en tres de los seis (La Gruta 1, La Gruta 3 y La Gruta 6). Los restantes tipos de motivos se encuentran concentrados en pocos sitios pertenecientes a un único sector de la localidad: LAG1 (sitios La Gruta 2, La Gruta 3 y, principalmente, La Gruta 6).

Tabla 3. Clases y tipos de motivos presentes en LAG1 y LAG2.

\begin{tabular}{|c|c|c|c|c|}
\hline $\mathrm{CM}$ & TM & LAG1 & LAG2 & Total gral. \\
\hline \multirow{8}{*}{ Geométricos simples } & cuadrado radiado & 1 & - & 1 \\
\hline & circunferencia radiada & 1 & - & 1 \\
\hline & línea curva & 2 & - & 2 \\
\hline & línea sinuosa & 1 & - & 1 \\
\hline & meandro & 4 & - & 4 \\
\hline & óvalo & 2 & - & 2 \\
\hline & zigzag & 2 & - & 2 \\
\hline & zigzag doble & 1 & - & 1 \\
\hline \multirow{3}{*}{ Manos } & mano contorneada & 5 & - & 5 \\
\hline & mano negativa & 18 & 26 & 44 \\
\hline & mano positiva & 5 & - & 5 \\
\hline Pisadas & tridígito & 28 & 1 & 29 \\
\hline \multirow{2}{*}{ Geométricos Puntiformes } & puntos en líneas rectas paralelas & 1 & - & 1 \\
\hline & puntos forma indeterminada & 2 & - & 2 \\
\hline \multirow{4}{*}{ Otros } & arrastre de dedo & 2 & - & 2 \\
\hline & arrastres de dedos paralelos múltiples (+ de 2$)$ & 3 & - & 3 \\
\hline & mancha & 36 & 6 & 42 \\
\hline & grafiti & 3 & - & 3 \\
\hline Total general (sin grafitis) & & 114 & 33 & 147 \\
\hline Total general (con grafitis) & & 117 & 33 & 150 \\
\hline
\end{tabular}




\begin{tabular}{|c|c|c|}
\hline CLASE DE MOTIVOS & TIPOS DE MOTIVOS & GRÁFICO \\
\hline \multirow{8}{*}{ Geométricos simples } & Cuadrado radiado & \\
\hline & Circunferencia radiada & \\
\hline & Línea curva & \\
\hline & Línea sinuosa & \\
\hline & Meandro & \\
\hline & Ovalo & \\
\hline & Zigzag & \\
\hline & Zigzag doble & \\
\hline \multirow{3}{*}{ Manos } & Mano contorneada & \\
\hline & Mano negativa & \\
\hline & Mano positiva & \\
\hline Pisadas & Tridígito & \\
\hline \multirow{2}{*}{ Puntiformes } & Puntos en líneas rectas paralelas & :::::::::::: \\
\hline & Puntos forma indeterminada & 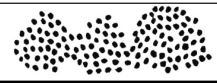 \\
\hline \multirow{4}{*}{ Otros } & Arrastre de dedo & \\
\hline & $\begin{array}{l}\text { Arrastres de dedos paralelos } \\
\text { múltiples }(+ \text { de } 2)\end{array}$ & \\
\hline & Mancha & \\
\hline & Grafiti & CHICHITA \\
\hline
\end{tabular}

Fig. 12. Repertorio de tipos y clases de motivos analizados en ambos sectores.

En cada sector la técnica más frecuentemente utilizada para la ejecución de los motivos es diferente: pintura en positivo para el caso de LAG1 $(\mathrm{n}=58=50,9 \%)$ y pintura en negativo para LAG2 $(\mathrm{n}=26=78,8 \%)$. Adicionalmente, sólo LAG1 posee motivos grabados ( $n=4=3,5 \%$ ) (Tabla 4 y Fig. 13).

En cuanto a las superposiciones de motivos, LAG1 posee mayor número de superposiciones que LAG2 ( $n=5$ vs. $n=3$; Tabla 2), lo cual es esperable dado su mayor frecuencia de sitios con arte, paneles y motivos. Sin embargo, a pesar del mayor número de sitios con arte, todas las superposiciones de LAG1 se concentran en pocos paneles $(n=3)$ de un solo sitio (La Gruta 6), mientras que en LAG2 se distribuyen entre paneles $(n=3)$ de sus dos sitios (La Gruta 1: $n=1$; La Gruta 4: $n=2$ ). Los casos de superposición registrados en LAG1 incluyen: tridígitos de color rojo oscuro sobre manchas de color rojo $(n=2)$ y rojo claro $(n=1)$, mano contorneada roja oscura sobre mano contorneada roja oscura $(n=1)$ y mano negativa roja sobre mano negativa de color 
Tabla 4. Tipos de motivos por técnicas en LAG1 y LAG2. Referencias: GI=grabado inciso; $\mathrm{PN}=$ pintura negativa; $\mathrm{PP}=$ pintura positiva; $\mathrm{P}=$ pintura indeterminable.

\begin{tabular}{|c|c|c|c|c|c|}
\hline Sector & TM & PP & $\mathrm{PN}$ & GI & $\mathrm{P}$ \\
\hline \multirow[t]{17}{*}{ LAG1 } & cuadrado radiado & 1 & - & - & - \\
\hline & circunferencia radiada & 1 & - & - & - \\
\hline & línea curva & 2 & - & - & - \\
\hline & línea sinuosa & 1 & - & - & - \\
\hline & meandro & 4 & - & - & - \\
\hline & óvalo & - & - & 2 & - \\
\hline & zigzag & 2 & - & - & - \\
\hline & zigzag doble & 1 & - & - & - \\
\hline & mano contorneada & 5 & - & - & - \\
\hline & mano negativa & - & 18 & - & - \\
\hline & mano positiva & 5 & - & - & - \\
\hline & tridígito & 26 & - & 2 & - \\
\hline & puntos en líneas rectas paralelas & 1 & - & - & - \\
\hline & puntos forma indeterminada & 2 & - & - & \\
\hline & arrastre de dedo & 2 & - & - & - \\
\hline & arrastres de dedos paralelos múltiples (+ de 2$)$ & 3 & - & - & - \\
\hline & mancha & 2 & - & - & 34 \\
\hline \multicolumn{2}{|c|}{ Subtotal LAG1 } & 58 & 18 & 4 & 34 \\
\hline \multirow[t]{3}{*}{ LAG2 } & mano negativa & - & 26 & - & - \\
\hline & tridígito & 1 & - & - & - \\
\hline & mancha & - & - & - & 6 \\
\hline \multicolumn{2}{|c|}{ Subtotal LAG2 } & 1 & 26 & - & 6 \\
\hline \multicolumn{2}{|c|}{ Total general } & 59 & 44 & 4 & 40 \\
\hline
\end{tabular}

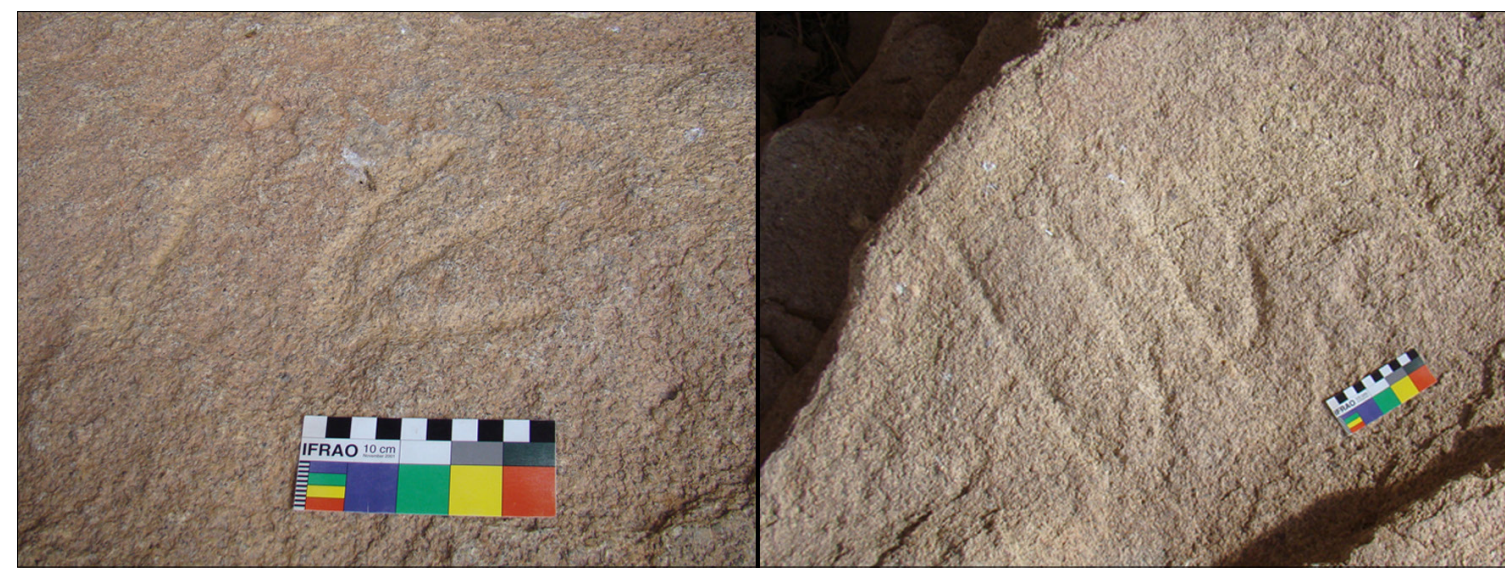

Fig. 13. Motivos grabados del sitio La Gruta 3 localizado en el afloramiento de areniscas de Laguna 1. 
rojo claro $(n=1)$. En LAG2 las superposiciones registradas consisten en mano negativa de color rojo oscuro sobre mano negativa de color rojo negruzco $(\mathrm{n}=1)$, mano negativa roja sobre mano negativa roja $(n=1)$ y tridígito rojo sobre mano negativa de color marrón rojizo claro $(n=1)$. En todos los casos las superposiciones involucran exclusivamente motivos pintados, no grabados.

\section{DISCUSIÓN Y CONCLUSIONES}

Los resultados de los análisis realizados sobre el arte rupestre de dos sectores de la localidad La Gruta, muy cercanos entre sí y relativamente similares en cuanto a recursos ofrecidos $y$ abrigos rocosos potencialmente utilizables por las poblaciones cazadorasrecolectoras, muestran diferencias a escalas de sitios, de paneles y de motivos (Tabla 5). Estas diferencias nos permiten pensar en la existencia de dos formas distintas de marcación visual del espacio en dos sectores relativamente similares de una pequeña localidad.

En el caso del arte rupestre de LAG2 es posible observar un patrón de marcación visual del espacio compuesto por:
1. un bajo número de sitios con arte rupestre, 2. con un bajo aprovechamiento de la extensión del afloramiento para producir arte, 3. localización de los sitios en pequeños aleros (incapaces de albergar muchos individuos) con buena visibilidad de la laguna y sus alrededores, 4. paneles conformados a partir de pocos motivos, tipos y clases de motivos, distribuidos de forma relativamente homogénea entre los sitios (similares frecuencias de paneles por sitio),

5. un bajo número de motivos, de tipos y clases de motivos (menor diversidad) y de técnicas, y

6. una baja cantidad de superposiciones.

Todas estas tendencias dan cuenta de una baja inversión de tiempo y energía acumulada en la producción de arte rupestre y marcación visual del espacio, consistente con una estrategia de utilización del sector predominantemente logística (pocos individuos durante cortos o breves periodos de ocupación).

Diferente es el caso de LAG1 donde es posible observar un patrón de marcación visual del espacio conformado por:

Tabla 5. Síntesis de diferencias y similitudes entre LAG1 y LAG2.

\begin{tabular}{|c|c|c|c|}
\hline & & LAG1 & LAG2 \\
\hline \multirow{9}{*}{ 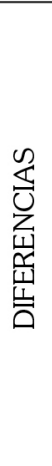 } & Frecuencia de sitios con arte rupestre & $\uparrow$ & $\downarrow$ \\
\hline & Distribución/concentración de sitios & $\uparrow$ Distribución & $\uparrow$ Concentración \\
\hline & Frecuencia de paneles & $\uparrow$ & $\downarrow$ \\
\hline & Frecuencia de motivos, tipos y clases & $\uparrow$ & $\downarrow$ \\
\hline & Frecuencia de técnicas & $\uparrow$ & $\downarrow$ \\
\hline & Superposiciones & $\uparrow$ & $\downarrow$ \\
\hline & Tipo de motivo más frecuente & Tridígitos & Manos negativas \\
\hline & Técnica más frecuente & Pintura positiva & Pintura negativa \\
\hline & Indice NTM/NM & $\uparrow$ & $\downarrow$ \\
\hline 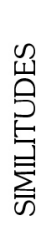 & $\checkmark$ predominio de la técnica de pintura & en los paneles & de las lagunas \\
\hline
\end{tabular}

Referencias: $\uparrow=$ más; $\downarrow=$ menos. 
1. una elevada frecuencia de sitios con arte rupestre,

2. con aprovechamiento de toda la extensión del afloramiento para producir arte,

3. localización de los sitios en aleros pequeños y algunos grandes (capaces de albergar muchos individuos) con buena visibilidad de la laguna y sus alrededores,

4. una mayor frecuencia de paneles, los cuales combinan más motivos, más tipos y clases de motivos, distribuidos de forma más heterogénea entre los sitios (con un solo sitio -La Gruta 6- que concentra la mayor cantidad de paneles y los paneles con mayor cantidad de motivos, tipos y clases),

5. una mayor cantidad de motivos, de tipos y clases de motivos (mayor diversidad) y de técnicas,

6. una mayor cantidad de superposiciones.

Estas tendencias dan cuenta de una mayor inversión de tiempo y energía acumulada en la producción de arte rupestre y marcación visual del espacio, concordante con una estrategia de utilización residencial del sector (más individuos, durante períodos de ocupación más largos y/o durante más períodos reiterados). Adicionalmente, considerando que en LAG1 un solo sitio (La Gruta 6) acumula las frecuencias más elevadas de paneles ${ }^{6}$ ( $n=13=52 \%)$, motivos $(n=75=65,8 \%)$, tipos de motivos ( $n=14$ de 18 ), clases de motivos ( $n=4$ de 5) y superposiciones ( 5 de 5), no sería desatinado pensar este locus como el centro de ocupación residencial de todo el sector o, en su defecto, el sitio lindante La Gruta 3, que también es un alero de gran tamaño en el cual ya se han detectado ocupaciones residenciales para momentos tardíos. Lamentablemente, el carácter exploratorio de esta afirmación será difícil de testear mediante excavaciones dado que La Gruta 6 fue el lugar escogido para el asentamiento de las primeras construcciones de la estancia y las expectativas de perturbación del registro estratigráfico son muy altas por la presencia de cimientos, raíces de plantas exóticas y eventos de desborde de la laguna que se habrían llevado consigo parte de los

6 Incluyendo los paneles que combinan mayor cantidad de motivos, tipos y clases de todo el sector y la localidad.

7 Cabe destacar que los materiales arqueológicos recuperados sedimentos (Brook et al. 2013, 2015).

En síntesis, en función de los conceptos expuestos en el marco teórico, si para los sitios logísticos la expectativa es: a) que ocurran en pequeños reparos (capaces de albergar grupos pequeños de individuos) y b) que incluyan una producción rupestre menos diversa (menos motivos, menor variabilidad de motivos) (Aschero, 1997), entonces el patrón de marcación visual del espacio mediante imágenes rupestres de LAG2 es consistente con un modelo de ocupación predominantemente logística. Por su parte, si para los sitios residenciales la expectativa es: a) que ocurran en reparos grandes (capaces de albergar más individuos) y b) que incluyan una producción rupestre más elevada en cantidad y diversidad, entonces el patrón de marcación visual del espacio de LAG1 es consistente con un modelo de ocupación residencial ${ }^{7}$ (Aschero, 1997).

En el caso de la LAG2 los resultados de los análisis realizados son concordantes con la información estratigráfica proveniente del sitio La Gruta 1 (artefactos líticos pequeños -desechosproducto de estadios finales de manufactura y reactivación de instrumentos, conjuntos de carbones y estructuras de combustión acotadas y baja cantidad de restos óseos animales), el cual fue interpretado como locus de una secuencia de ocupaciones breves, discontinuas, asociadas con la realización de actividades extractivas vinculadas a la caza de guanacos (Franco et al. 2010). El bajo número de sitios y motivos registrados en el sector, sumado a la exigua variabilidad morfológica y técnica de los mismos, el predominio de paneles compuestos por pocos motivos y las escasas superposiciones, muestran una baja intensidad de producción rupestre acumulada, posiblemente consistente con un patrón de agregación de eventos discretos de ejecución de arte a través del tiempo, susceptible de ser asociada con la baja intensidad de ocupación humana del sector.

En el caso de LAG1 los resultados obtenidos en este trabajo son concordantes con la información estratigráfica proveniente de La Gruta 3 para el lapso comprendido entre ca. 400 a 200 años AP (tasas de depositación elevadas, mayor diversidad

hasta el momento en las excavaciones realizadas en ambos sectores sólo permiten pensar en actividades relacionadas con la vida cotidiana. 
artefactual, representación de estadios iniciales de manufactura y un fogón de gran tamaño), momento para el cual se ha planteado que el sitio habría sido utilizado para la realización de actividades múltiples vinculadas con ocupaciones de carácter residencial (Cirigliano, 2016). La información generada por las excavaciones realizadas en el sector (sitios La Gruta 2 y La Gruta 3) no es suficiente aún para establecer relaciones entre intensidad de producción rupestre $e$ intensidad de ocupación. Por el momento, los escasos materiales recuperados en La Gruta 2 (un raspador, escasos desechos líticos y restos óseos animales datados en ca. 7.500 años AP; ver Franco et al. 2013), invitan a descartar -preliminarmente- la hipótesis de una ocupación continua o repetidamente residencial del sector. Lo mismo ocurre con el arte rupestre que, si bien exhibe una mayor intensidad de producción acumulada a través del tiempo, muestra un patrón de acumulación irregular. En este sentido, las bajas frecuencias de paneles con muchos motivos (seis a 23 motivos: $n=6=24 \%$ ) en comparación con paneles conformados por pocos motivos (uno a tres motivos: $n=12=42 \%$ ), sumado al bajo número de superposiciones registradas y la concentración estas superposiciones en pocos paneles $(n=3)$ de un solo sitio, que poseen muchos motivos ( $n=8$ y $n=23$ ), indican un patrón irregular de acumulación de arte compuesto por: eventos discretos de producción de pocos motivos por panel y eventos discretos de producción de muchos motivos por panel. En consonancia con la información estratigráfica proveniente de La Gruta 3, es posible que algunos de los paneles con mayor cantidad de motivos (principalmente los compuestos por tridígitos, manos contorneadas y motivos geométricos pintados), puedan estar asociados a las ocupaciones humanas más tardías del sector, dado que estos tipos de motivos comparten similitudes en sus colores (rojo y rojo oscuro), alta integridad morfológica, alta intensidad de color/contraste con la roca soporte y algunos de ellos (por ej. tridígitos y manos contorneadas) se sitúan siempre por arriba de otros motivos en las superposiciones.

Es esperable que con el avance de las investigaciones y la realización de nuevas excavaciones se genere un cúmulo mayor de información que permita establecer relaciones más precisas entre intensidad de producción rupestre e intensidad de ocupación humana del sector. Hasta ese momento, los resultados obtenidos en este trabajo pueden ser utilizados como hipótesis preliminares para el direccionamiento de los estudios rupestres y excavaciones a realizarse en el futuro.

\section{AGRADECIMIENTOS}

Este trabajo se desarrolló en el marco de una Beca Interna Doctoral de Conicet. Los trabajos de campo fueron realizados en el marco de los proyectos PIP 11420090100356 (CONICET), PIP 1122012010447CO (CONICET) y PICT 2015-2038 (MINCYT-ANPCYT), dirigidos por Dra. N. Franco. Minera Triton S.A. y Minera Piedra Grande S.A. colaboraron con alojamiento, comida y movilidad durante los trabajos de campo. Agradezco a la Secretaria de Turismo y a la Secretaría de Cultura y Deportes de Gdor. Gregores por su predisposición, interés y apoyo hacia nuestra investigación, en especial a los señores Pablo Ramírez y Marcelo Cebeira. Un especial agradecimiento para Dánae Fiore y Natalia Cirigliano por su colaboración en las tareas de registro del arte rupestre de La Gruta. Este trabajo se vio nutrido por las sugerencias, comentarios y correcciones de las Dras. Dánae Fiore y Nora V. Franco, quienes han enriquecido progresivamente las diferentes versiones del manuscrito. Finalmente, agradezco a los evaluadores del trabajo por sus valiosas sugerencias y correcciones.

\section{BIBLIOGRAFÍA}

Acevedo, A., Fiore, D., Franco, N. V., \& Ocampo, M. (20122014). Arte y espacio. Estructuración de los repertorios de arte rupestre en los cañadones Yaten Guajen y El Lechuza (Margen Norte del Río Santa Cruz, Patagonia, Argentina). Mundo de Antes, 8, 9-33.

Aschero, C. (1988). Pinturas rupestres, actividades y recursos naturales; un encuadre arqueológico. En $\mathrm{H}$. Yacobaccio (ed.), Arqueología Contemporánea Argentina. Actualidad y Perspectivas (pp. 109-145). Buenos Aires: Ediciones Búsqueda.

Aschero, C. (1996). ¿Adónde van esos guanacos? En J. Gómez Otero (Ed.), Arqueología solo Patagonia. Ponencias de las II Jornadas de Arqueología de la Patagonia (pp. 153-162). Puerto Madryn: CENPAT-CONICET. 
Aschero, C. (1997). De cómo interactúan emplazamientos, conjuntos y temas. Actas XI Congreso Nacional de Arqueología Argentina. Revista del Museo de Historia Natural de San Rafael, 16(1-4), 17-28.

Binford, L. (1980). Willow smoke and dogs. Tails: hunter gatherer settlement systems and archaeological site formation. American Antiquity, 45(1), 4-20.

Bradley, R., Criado Boado, F., \& Fabregas Valcarce, R. (1994). Rock art research as landscape archaeology: a pilot study in Galicia, north-west Spain. World Archaeology, 25(3), 374-390.

Brook, G. A., Mancini, M. V., Franco, N. V., Bamonte, F., \& Ambrústolo, P. (2013). An examination of possible relationships between paleoenvironmental conditions during the Pleistocene-Holocene transition and human occupation of southern Patagonia (Argentina) east of the Andes, between $46^{\circ}$ and $52^{\circ}$ S. Quaternary International, 305, 104-118.

Brook, G. A., Franco, N. V., Ambrústolo, P., Mancini, M. V., Wang, L., \& Fernández, P. M. (2015). Evidence of the earliest humans in the Southern Deseado Massif (Patagonia, Argentina), Mylodontidae, and changes in water availability. Quaternary International, 363, 107-125.

Carden, N. (2008). Imágenes a través del tiempo. Arte rupestre y construcción social del paisaje en la Meseta Central de Santa Cruz. Ciudad Autónoma de Buenos Aires: Sociedad Argentina de Antropología.

Cirigliano, N. A. (2016). A través de sendas y caminos: un estudio sobre los cambios en la circulación $y$ movilidad humana entre las cuencas de los ríos Chico -curso inferior y medio- y Santa Cruz durante los últimos 2000 años (Provincia de Santa Cruz, Argentina). Tesis doctoral. Buenos Aires: Facultad de Filosofía y Letras, Universidad de Buenos Aires.

Conkey, M. (1984). To find ourselves: art and social geography of prehistoric hunter-gatherers. En C. Shire (Ed.), Past and present in Hunter-Gatherer studies (pp. 253276). New York: Academic Press.

Fiore, D. (2002). Body painting in Tierra del Fuego. The power of images in the uttermost part of the world. Tesis doctoral. Londres: Institute of Archaeology, University of London.

Fiore, D. (2006). Poblamiento de Imágenes: arte rupestre y colonización de la Patagonia. Variabilidad y ritmos de cambio en tiempo y espacio. En D. Fiore, \& M. Podestá (Eds.), Tramas en la Piedra. Producción y usos del Arte Rupestre (pp. 43-61). Buenos Aires: AINA, SAA, WAC.

Fiore, D. (2009). La materialidad del arte. Modelos económicos, tecnológicos y cognitivo-visuales. En R. Barberena, K.
Borrazo \& L. A. Borrero (Eds.), Perspectivas actuales en arqueología argentina (pp. 121-154). Buenos Aires: Conicet-Imhicihu.

Fiore, D. (2011). Materialidad visual y arqueología de la imagen. Perspectivas conceptuales y propuestas metodológicas desde el sur de Sudamérica. Boletín del Museo Chileno de Arte Precolombino, 16(2), 101-119.

Fiore, D. (2016). Las dimensiones espaciales del arte parietal. Estado actual de las investigaciones desde el Cono Sur y propuesta de síntesis metodológica. En A. M. Rocchietti, F. Oliva, F. Solomita \& M. Algrain (Eds.), Imágenes rupestres, lugares y regiones (pp. 51-62). Rosario: CEAR-CEAH.

Fiore, D., \& Acevedo, A. (2016). El Trabajo del arte. Una evaluación de la inversión laboral en la producción de arte rupestre: el caso del Cañadón Yaten Guajen (Santa Cruz, Patagonia, Argentina). En A. M. Rocchietti, F. Oliva, F. Solomita \& M. Algrain (Eds.), Imágenes rupestres: lugares y regiones (pp. 485-504). Rosario: CEAR-CEAH.

Fiore, D., \& Acevedo, A. (2017). Paisajes rupestres. La identificación de patrones de producción y distribución de arte parietal en escalas espaciales amplias (cañadón Yaten Guajen, Santa Cruz, Patagonia Argentina). Revista Arqueología, 24(2), 177-207.

Franco, N. V. (2007). Variaciones regionales y diseños artefactuales compartidos en el sur de Patagonia continental y norte de Tierra del Fuego (Informe de tareas realizadas en el marco del proyecto UBACyT F 140). Santa Cruz Dirección de Patrimonio de la Provincia de Santa Cruz.

Franco, N. V., \& Cattaneo, R. G. (2009). Trabajos arqueológicos en el área de La Gruta (Gobernador Gregores, Santa Cruz, Argentina). Manuscrito inédito.

Franco, N. V., Martucci, M., Ambrústolo, P., Brook, G., Mancini, M. V., \& Cirigliano, N. A. (2010). Ocupaciones humanas correspondientes a la transición PleistocenoHoloceno al sur del Macizo del Deseado: el área de La Gruta (provincia de Santa Cruz, Argentina). Relaciones de la Sociedad Argentina de Antropología, 35, 301308.

Franco, N. V., Ambrústolo, P., \& Cirigliano, N. A. (2012). Disponibilidad de materias primas líticas silíceas en el extremo sur del macizo del Deseado: Los casos de La Gruta y Viuda Quenzana (Provincia de Santa Cruz, Argentina). Magallania, 40, 279-286.

Franco, N. V., Ambrústolo, P., Acevedo, A., Cirigliano, N. A., \& Vommaro, M. (2013). Prospecciones en el sur del Macizo del Deseado (Provincia de Santa Cruz, 
Argentina). Los casos de La Gruta y Viuda Quenzana. En A. F. Zangrando; R. Barberena; A. Gil; G. Neme; M. Giardina; L. Luna; C. Otaola; S. Paulides; L. Salgán, \& A. Tivoli (comps.), Tendencias teóricometodológicas y casos de estudio en la arqueología de Patagonia (pp. 371-378). Buenos Aires: Museo de Historia Natural de San Rafael, SAA \& INAPL.

Gradin, C. (1978). Algunos aspectos del análisis de las manifestaciones rupestres. Revista del Museo Provincial de Neuquén, 1, 120-133.

Gradin, C., \& Aguerre, A. M. (1983). Arte rupestre del "Área de La Martita" sección del departamento Magallanes provincia de Santa Cruz. Relaciones de la Sociedad Argentina de Antropología, 15, 195-223.

Harman, J. (2008 [2005]). Using Decorrelation Stretch to Enhance Rock Art Images. Recuperado de: http:// www.dstretch.com/AlgorithmDescription.html.

Hernández Llosas, M. I. (1985). Diseño de investigación para representaciones rupestres. En Programa de Investigación y Documentación de Arte Rupestre Argentino (pp. 9-65). Buenos Aires: Ed. FECIC.

Jochim, M. (1983). Palaeolithic cave art in ecological perspective. En G. Bailey (Ed.), Hunter-gatherer economy in prehistory (pp. 212-219). Cambridge: Cambridge University Press.

Llamazares, A. M. (1992). Imágenes e Ideología: algunas sugerencias para su estudio arqueológico. En A. S. Goldsmith, S. Garvie, D. Selin \& J. Smith (Eds.), Ancient Images, Ancient Thought. The Archaeology of Ideology (pp. 151-158). Calgary: Ed. Chacmool \& Archaeological Society of Alberta.

Loendorf, L. (2001). Rock art recording. En D. Whitley (Ed.), Handbook of Rock Art Research (pp. 55-79). Oxford: AltaMira Press.

Mancini, M. V., Franco, N. V., \& Brook, G. A. (2013). Paleoenvironment and early human occupation of southernmost South America (South Patagonia, Argentina). Quaternary International, 299, 13-22.

Menghin, O. (1952). Las pinturas rupestres de la Patagonia. Runa, 5(1-2), 5-22.

Menghin, O. (1957). Los estilos del arte rupestre de Patagonia. Acta Prehistórica, 1, 57-87.

Panza, J. L., \& Marín, G. (1998). Hoja Geológica 4969-I Gobernador Gregores, Provincia de Santa Cruz. Programa Nacional de Cartas Geológicas de la República Argentina 1:250.000. Boletín $\mathrm{N}^{\circ} 239$. Buenos Aires: Secretaría de Minería de la Nación. Dirección Nacional del Servicio Geológico.

Re, A. (2010). Representaciones rupestres en mesetas altas de la provincia de Santa Cruz. Circulación de información en espacios de uso estacional. Tesis doctoral. Buenos Aires: Facultad de Filosofía y Letras, Universidad de Buenos Aires.

Vector Argentina S.A. (2005). Estudios de la línea de base del proyecto Manantial. Informe arqueológico. En: MWH. Informe de Impacto Ambiental Proyecto Manantial Espejo. Gobernador Gregores, Provincia de Santa Cruz, Argentina. Noviembre de 2005. 
